\title{
Productivity for sustainable growth in Malaysian oil palm production: a system dynamics modeling approach
}

\begin{abstract}
Productivity is posited as the key to shape a more sustainable oil palm industry. This study, through a systemic perspective, explores the main drivers of productivity growth and its impacts on its associated factors using a system dynamics model. Of all four simulations, research and development (R\&D) intervention is demonstrated to enhance oil palm production albeit at the cost of seemingly unstoppable land loss. This, in turn, leads to lower carbon emissions. Automation and mechanization are found effective in reducing farm operating cost. These findings suggest that $\mathrm{R} \& \mathrm{D}$ is key, and related policy options are discussed for steering the sustainability and growth of oil palm production in Malaysia.
\end{abstract}

Keyword: Oil palm; Productivity; Production; Sustainability; Carbon emission; System dynamics 